\title{
REFORMA PSIQUIÁTRICA E SUA ARTICULAÇÃO COM O PROCESSO DE TRABALHO DO ENFERMEIRO
}

\author{
Autora: Ângela Maria Corrêa Gonçalves \\ Orientador: Francisco Carlos Felix Lana
}

\begin{abstract}
RESUMO: Este é um estudo qualitativo, que teve como objeto a organização do processo de trabalho do enfermeiro atuante em dois hospitais psiquiátricos da rede privada do municipio de Juiz de Fora, MG. O novo paradigma da reforma psiquiátrica acarretou a necessidade de reorganizar serviços, criar novas modalidades de atendimento e reformular a organização do trabalho. Com o objetivo de analisar o discurso dos enfermeiros acerca da reforma psiquiátrica e a articulação dela sobre seu fazer cotidiano, tentamos identificar os seus determinantes que interferem no exercício de sua prática, na assistência ao doente mental, analisando as contradições entre o modo de pensar e operar do enfermeiro. Partindo do pressuposto que a enfermagem é uma prática social, portanto articulada às demais práticas de saúde, conduzimos a investigação à luz do referencial teórico-metodológico do materialismo histórico dialético, que considera a historicidade e a dinamicidade dos fenômenos sociais. Tomamos como base o conceito de "processo tecnológico de organização do trabalho" desenvolvido por MENDES GONÇALVES (1986), por ser uma opção que apresenta fins práticos, possibilitando a investigação das transformações ocorridas na assistência ao indivíduo portador de doença mental, a partir da reforma psiquiátrica. A capacitação da realidade empírica se deu através de entrevistas semi-estruturadas e da observação direta. Foram sujeitos desse estudo dez enfermeiros lotados nas referidas instituições. O resultado nos revela que a assistência de enfermagem que encontramos nessas instituições não pode ser reconhecida como "psiquiátrica"; que o enfermeiro tem grande dificuldade em definir sua prática e justifica sua ausência na assistência direta com a sobrecarga de atividades "burocráticas", no sentido mais amplo dessa palavra. Concluímos que os instrumentos que o enfermeiro dispõe para aproximar e transformar seu objetivo e atingir sua finalidade são: a organização do ambiente hospitalar através de mecanismos disciplinares e a organização dos agentes da equipe de enfermagem através de mecanismos controladores. O trabalho que vem sendo desenvolvido pelo enfermeiro nestas instituições psiquiátricas confronta-se com os principios da reforma psiquiátrica, e o rompimento com o modelo tradicional de cuidar implica na formação de uma nova consciência, na reestruturação de novos saberes, o que resultará na transformação da prática.
\end{abstract}

\section{TRABALHO DO ENFERMEIRO EM UM CONTEXTO DE MUDANÇAS ORGANIZACIONAIS}

\author{
Autora: Maria da Graça Fonseca \\ Orientadora: Marilia Alves
}

RESUMO: A intensidade e a velocidade das mudanças, freqüentemente, ocasionam insegurança nos indivíduos envolvidos e desestabilização das organizações que buscam se adaptar para alcançar novos patamares de estabilidade e reduzir o impacto das mudanças no cotidiano de trabalho. O Hospital Universitário, no bojo das mudanças do setor saúde, vem implementando mudanças significativas e buscando vencer as resistências, e a Enfermagem, enquanto grupo majoritário na organização, não pode ficar à margem. No entanto, parece-nos que a Divisão de Enfermagem e os enfermeiros não têm participado ativamente do processo, vindo a reboque do mesmo, submetendo-se às decisões de outros profissionais e sofrendo as suas conseqüências. Neste estudo, buscamos analisar o processo de mudanças que vêm ocorrendo no Hospital Universitário e seus reflexos no trabalho do enfermeiro. Para tal, realizamos um estudo qualitativo utilizando como base de análise o referencial teórico-metodológico do Materialismo Histórico Dialético. A captação da realidade empírica deu-se através da aplicação de um roteiro de entrevista semi-estruturada, aplicado a 13 enfermeiros que ocupavam cargos de direção, gerência de setor e de unidades de internação. Os dados foram submetidos a análise de discurso. Os resultados mostram que as mudanças em curso no hospital, tanto na perspectiva de longo prazo, contemplando os esforços para que o projeto do Centro de Atenção à Saúde (CAS) se torne uma realidade, como aquelas de médio e curto prazo, envolvendo aspectos políticos, gerenciais, tecnológicos e comportamentais, afetam direta ou indiretamente o trabalho da enfermagem. Percebe-se que, na maioria das vezes, o enfermeiro não tem sido chamado a participar do planejamento dessas mudanças, mesmo sendo um elemento intermediário que organiza o ambiente de trabalho e multiplica as informações para os demais membros da equipe de enfermagem. Verificaremos que as reações dos enfermeiros às mudanças vão do receio e insegurança em relação ao futuro até a resistência à mudança e adoção de atitudes defensivas. Mas, por outro lado, há, também, interesse e desejo de inserção no processo. No entanto, os enfermeiros ainda não estão organizados de forma a se antecipar às mudanças organizacionais e sentem-se perdidos no direcionamento de suas ações, levando a criação de

${ }^{1}$ Cópia das teses/dissertações solicitar informações pelo E-mail cepen@abennacional.org.br 